\title{
The proteasomal and apoptotic phenotype determine bortezomib sensitivity of non-small cell lung cancer cells Jens Voortman*1, Agnieszka Chęcińska ${ }^{1,2}$ and Giuseppe Giaccone ${ }^{1,3}$
}

\begin{abstract}
Address: ${ }^{1}$ Department of Medical Oncology, VU University Medical Center, 1081HV Amsterdam, the Netherlands, ${ }^{2}$ Department of Dermatology, University of Michigan, 4217 Comprehensive Cancer Center, 1500 East Medical Center Drive Ann Arbor, MI 48109-0314, USA and ${ }^{3}$ Medical Oncology Branch, National Cancer Institute, National Institutes of Health, 10 Center Drive, Bethesda, MD 20892-1906, USA

Email: Jens Voortman* - j.voortman@vumc.nl; Agnieszka Chęcińska - agnieszk@med.umich.edu; Giuseppe Giaccone - giacconeg@mail.nih.gov * Corresponding author
\end{abstract}

Published: 17 November 2007

Molecular Cancer 2007, 6:73 doi:10.1186/1476-4598-6-73
Received: 4 August 2007

Accepted: 17 November 2007

This article is available from: http://www.molecular-cancer.com/content/6/1/73

(c) 2007 Voortman et al; licensee BioMed Central Ltd.

This is an Open Access article distributed under the terms of the Creative Commons Attribution License (http://creativecommons.org/licenses/by/2.0), which permits unrestricted use, distribution, and reproduction in any medium, provided the original work is properly cited.

\begin{abstract}
Bortezomib is a novel anti-cancer agent which has shown promising activity in non-small lung cancer (NSCLC) patients. However, only a subset of patients respond to this treatment. We show that NSCLC cell lines are differentially sensitive to bortezomib, IC ${ }_{50}$ values ranging from 5 to 83 $\mathrm{nM}$. The apoptosis-inducing potential of bortezomib in NSCLC cells was found to be dependent not only on the apoptotic phenotype but also on the proteasomal phenotype of individual cell lines. Upon effective proteasome inhibition, $\mathrm{H} 460$ cells were more susceptible to apoptosis induction by bortezomib than SWI573 cells, indicating a different apoptotic phenotype. However, exposure to a low dose of bortezomib did only result in SWI573 cells, and not in H460 cells, in inhibition of proteasome activity and subsequent apoptosis. This suggests a different proteasomal phenotype as well. Additionally, overexpression of anti-apoptotic protein Bcl-2 in $\mathrm{H} 460$ cells did not affect the proteasomal phenotype of $\mathrm{H} 460$ cells but did result in decreased bortezomib-induced apoptosis. In conclusion, successful proteasome-inhibitor based treatment strategies in NSCLC face the challenge of having to overcome apoptosis resistance as well as proteasomal resistance of individual lung cancer cells. Further studies in NSCLC are warranted to elucidate underlying mechanisms.
\end{abstract}

\section{Findings}

Intracellular protein metabolism involves both synthesis as well as degradation of proteins. The vast majority of proteins is selectively degraded by the ubiquitin-proteasome system (UPS). The 26S proteasome complex is composed of a $20 \mathrm{~S}$ "core", a large protein complex that harbours the proteolytically active sites, and 19S "caps", which play a role in the recognition of poly-ubiquitinated protein substrates, targeted for degradation. Poly-ubiquitination involves covalent ligation of the target protein, by the sequential action of three enzymes, to a chain of ubiquitin molecules [1].

Growing awareness of the pivotal role of the UPS in normal cell physiology as well as in (malignant) disease propelled the development of proteasome inhibitors for therapeutic applications [2-4]. Bortezomib (Velcade) is the first clinically approved small molecule proteasome inhibitor. It reversibly binds and inhibits the chymotryptic-like proteolytic activity of the proteasome, localized 
within the $\beta_{5}$ subunit of the $20 \mathrm{~S}$ core. This results in disturbance of intracellular protein homeostasis by accumulation of poly-ubiquitinated proteins. Among other effects, this can trigger apoptosis, with a relative selectivity for malignant as opposed to normal cells [3].

Lung cancer is the most common cause of cancer-related death in the world [5]. Non-small cell lung cancer (NSCLC) consists of epithelial tumors, accounting for approximately $80 \%$ of lung carcinomas. Clinical studies showed promising activity of bortezomib in a subset of patients with non-small cell lung cancer (NSCLC) [6,7]. So far the exact molecular mechanism of resistance of NSCLC to bortezomib remains unclear [8-11]. Recently, adaptation of leukaemia and lymphoma cells to continuous exposure of bortezomib was reported to result from increased expression and altered subunit composition of the proteasome $[12,13]$. Furthermore, resistance was shown to be associated with increased expression of antiapoptotic Bcl-2 family member proteins and heat shock proteins [14-17]. In this study, we examined the effects of bortezomib in a panel of NSCLC cell lines. We observed differential activity of bortezomib in NSCLC cells regarding growth inhibition, the proteasome activity profile and apoptosis induction.

We first determined the anti-proliferative effect of a concentration range of bortezomib by MTT assay in a panel of NSCLC cell lines (Figure 1A). We observed differential sensitivity to bortezomib-induced growth inhibition, with $\mathrm{IC}_{50}$ values ranging from 5 to $83 \mathrm{nM}$. The p53 status did not correlate with sensitivity (Figure 1B). Next, to establish the apoptosis inducing potential of bortezomib, a sensitive cell line, SW1573, and a resistant cell line, H460, were selected for treatment and subsequent PI stainingbased FACS analysis to determine the subG $\mathrm{G}_{1}$ apoptotic fraction of the cell population. Additionally, the fractions of cells in the $G_{1}, S$ or $G_{2} M$ phase of the cell cycle were assessed.

As shown in Figure 2, upon exposure of SW1573 cells to a low concentration of bortezomib, $10 \mathrm{nM}$, cells went into $\mathrm{G}_{2} \mathrm{M}$ cell cylce arrest, whereas $\mathrm{H} 460$ cells remained predominantly in the $\mathrm{G}_{1}$ phase of the cell cycle. This finding suggested that the proteasome activity in $\mathrm{H} 460$ cells is not inhibited at $10 \mathrm{nM}$ of bortezomib, as proteasome inhibition typically results in $\mathrm{G}_{2} \mathrm{M}$ arrest $[18,19]$. Furthermore, $\mathrm{G}_{2} \mathrm{M}$ arrest in SW1573 and $\mathrm{H} 460$ cells was associated with increased expression of Mcl-1, which is known to be upregulated upon proteasome inhibition $[15,20]$. As shown in Figure 2, Mcl-1 is only upregulated in H460 cells when exposed to bortezomib at a high concentration (100 $\mathrm{nM}$ ), whereas Mcl-1 is upregulated in SW1573 cells also at a low concentration of bortezomib $(10 \mathrm{nM})$. Concordantly, treatment with bortezomib $10 \mathrm{nM}$ for $48 \mathrm{~h}$ led to significant apoptosis in SW1573 cells (18\%), but not in H460 cells. However, at a higher dose of bortezomib (50 to $100 \mathrm{nM}$ ), both SW1573 and $\mathrm{H} 460$ cells went into $\mathrm{G}_{2} \mathrm{M}$ arrest, resulting after $48 \mathrm{~h}$ in more apoptotic $\mathrm{H} 460$ cells (49\%) compared to SW1573 cells (32\%). Thus, upon effective induction of $\mathrm{G}_{2} \mathrm{M}$ cell cycle arrest, the apoptosis inducing potential of bortezomib was more pronounced

A.

B.

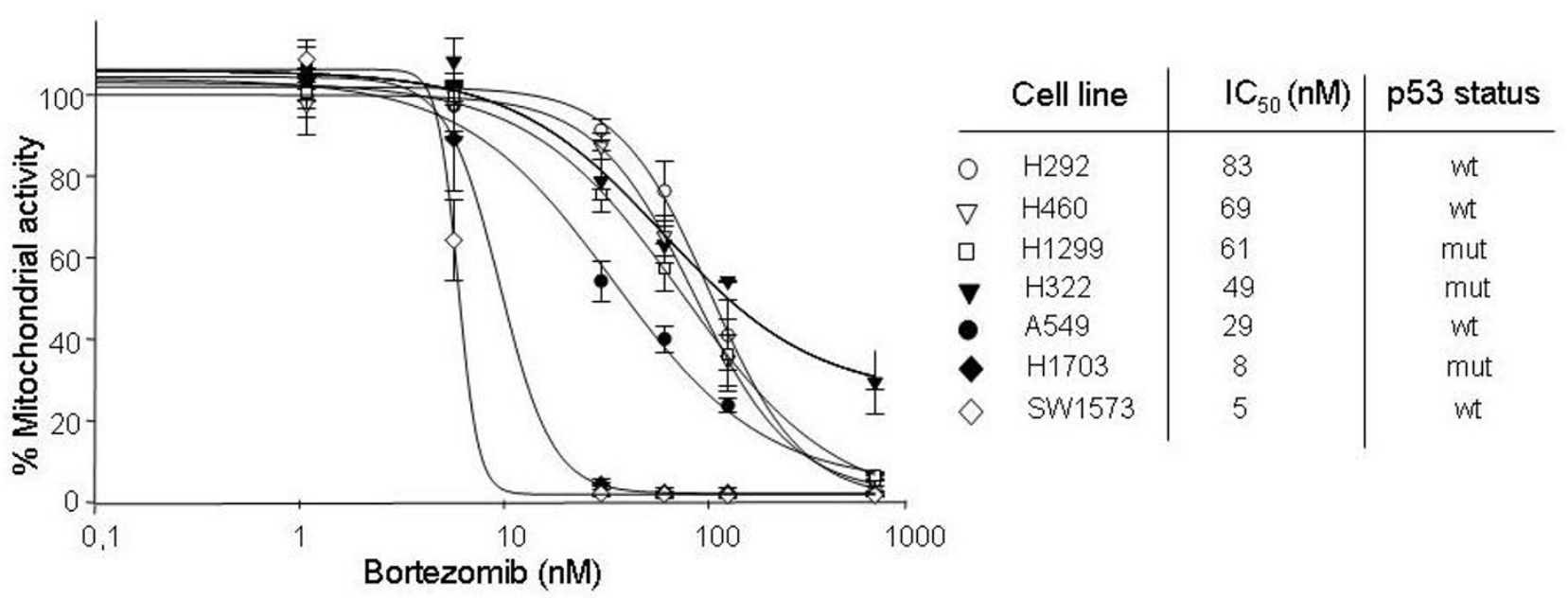

Figure I

Growth inhibition by bortezomib in NSCLC cells. (A) Growth curves (MTT assays) of NSCLC cells treated with different concentrations of bortezomib. Mean of at least three independent experiments, SD. (B) IC ${ }_{50}$ concentrations and p53 status of individual cell lines. Wt: wild type; mut: mutated. 

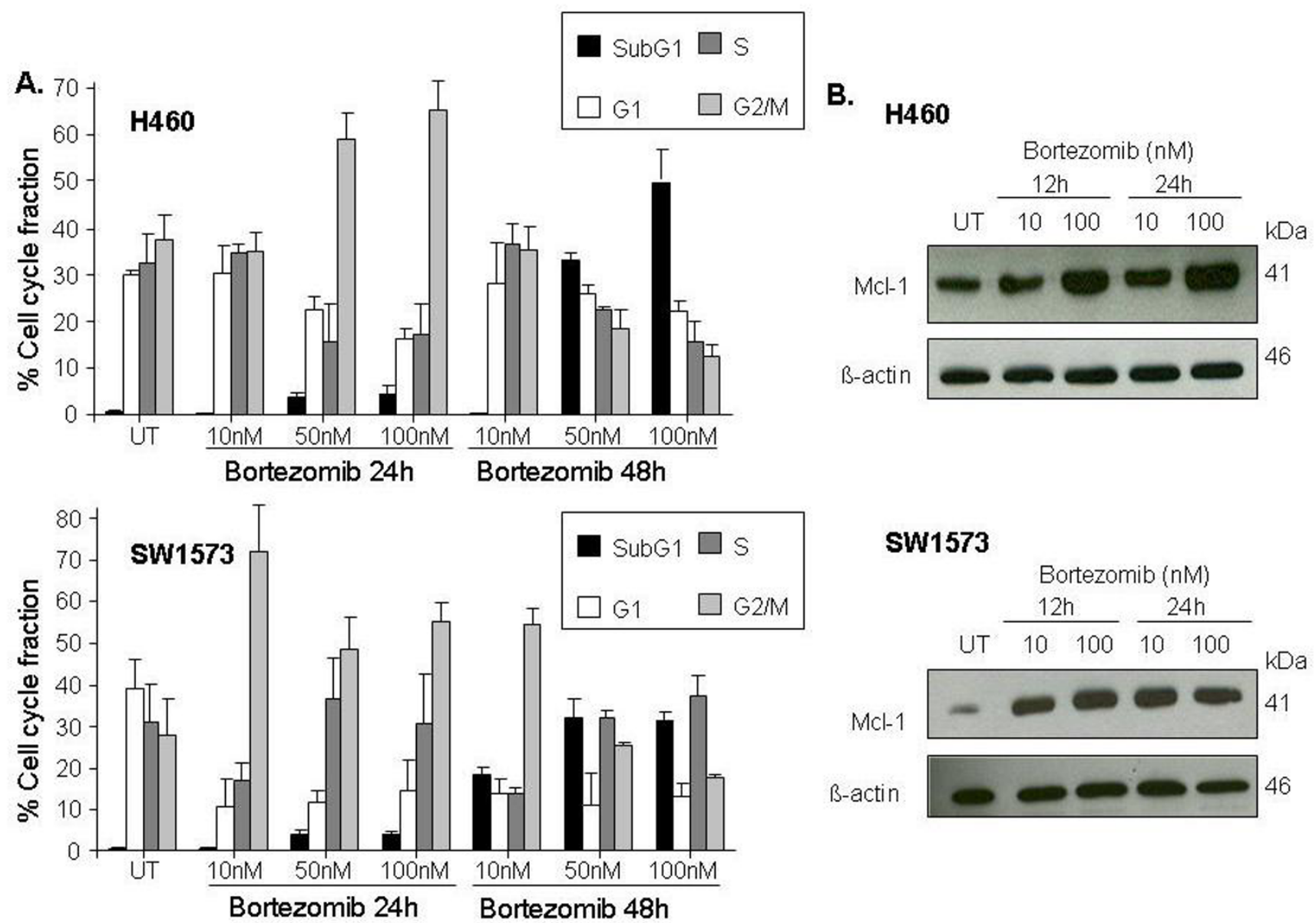

Figure 2

Induction of apoptosis and cell cycle arrest by bortezomib. (A) Effect of different concentrations of bortezomib on cell cycle progression of H460 and SWI573 cells upon 24 or 48 hours of exposure. Mean of at least three independent experiments, SD. Ut: untreated. (B) Time and concentration course Western blot analysis of total cell extracts of H460 and SWI573 cells showing the effect of treatment with bortezomib on the expression level of Mcl-I.

in $\mathrm{H} 460$ cells compared to SW1573 cells, indicating a different apoptotic phenotype. In contrast, SW1573 cells went into $G_{2} \mathrm{M}$ arrest at a lower threshold concentration of bortezomib than $\mathrm{H} 460$ cells, also indicating a different proteasomal phenotype of these two cell lines.

In order to further evaluate the mechanism of resistance to bortezomib, proteasome activity was measured upon treatment with various concentrations of bortezomib in H460, SW1573 and H460-Bcl-2 cells. H460-Bcl-2 cells, overexpressing anti-apoptotic factor $\mathrm{Bcl}-2$, have a more apoptosis resistant phenotype compared to the parental H460 cells [15].

As shown in Figure 3, the basal level of proteasome activity was about $10 \%$ lower in SW1573 cells compared to $\mathrm{H} 460$ and H460-Bcl-2 cells. Furthermore, at $10 \mathrm{nM}$ of bortezomib, proteasome inhibition occurred exclusively in SW1573 cells. In contrast, at $100 \mathrm{nM}$ of bortezomib the level of proteasome inhibition was similar in all cell lines. Overexpression of $\mathrm{Bcl}-2$ did not alter the basal proteasome activity nor its inhibition induced by bortezomib [15].

These observations confirmed a differential proteasomal phenotype comparing H460 and SW1573 cells and indicate that the proteasomal phenotype is independent of the apoptotic phenotype.

Bortezomib predominantly inhibits the chymotryptic-like activity of the $20 \mathrm{~S}$ proteasome, harboured in the $\beta_{5}$ subunit, and to a lesser extent the caspase-like activity harboured in the $\beta_{1}$ subunit $[21,22]$. We therefore next evaluated whether the relative sensitivity for proteasome 
A.

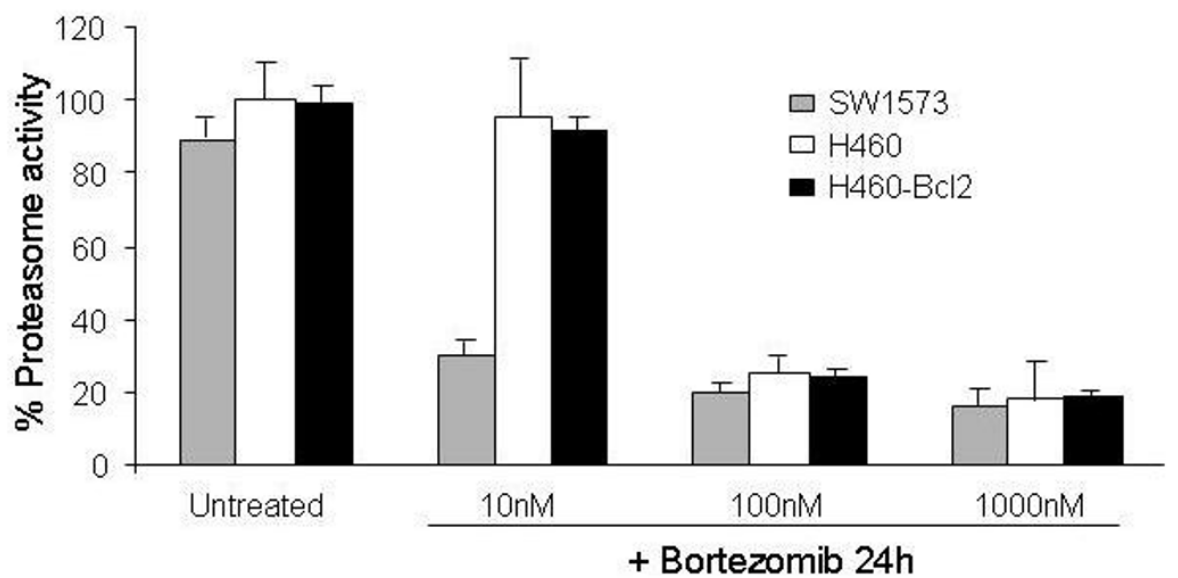

B.

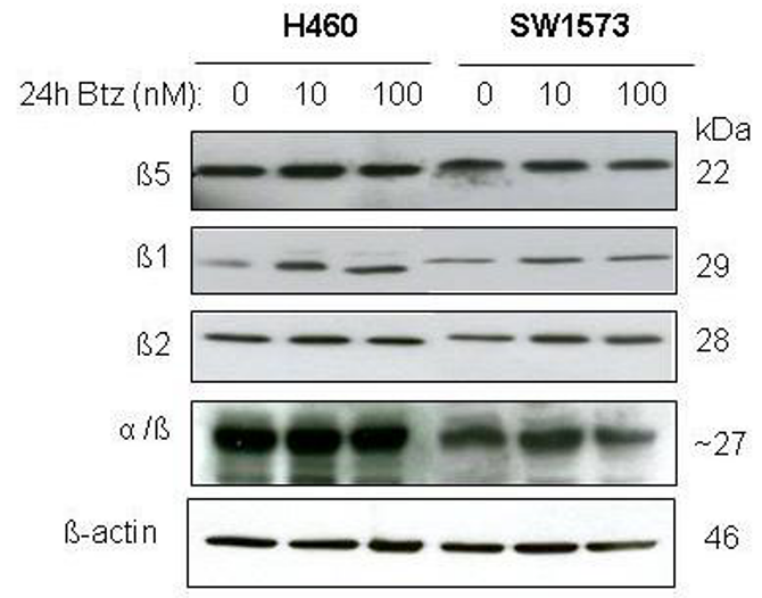

c.

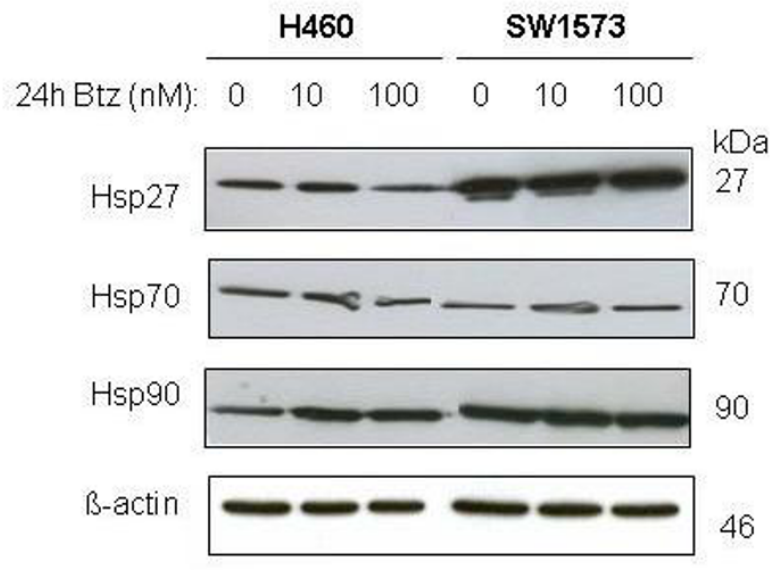

\section{Figure 3}

Proteasome activity and expression of catalytic subunits upon bortezomib treatment. (A) Intracellular proteasome activity in $\mathrm{H} 460, \mathrm{H} 460-\mathrm{Bcl}-2$ and SWI573 cells treated with a concentration range of bortezomib. Mean of at least three independent experiments, SD. (B) Time and concentration course Western blot analysis of total cell extracts of $\mathrm{H} 460$ and SWI573 cells showing the effect with treatment with bortezomib on the expression level of the 20S proteasome core $(\alpha / \beta)$, individual catalytic subunits: $\beta_{1, \beta 2}, \beta_{5}$ and $(C)$ heat shock proteins $\mathrm{Hsp} 27$, Hsp70 and $\mathrm{Hsp} 90$.

inhibition of SW1573 cells correlated with a decreased expression level of the 20S proteasome and its individual catalytically active subunits, $\beta_{1}, \beta_{2}$ and $\beta_{5}$. As shown in Figure $3 \mathrm{~B}$, the expression level of the $\beta_{1}, \beta_{2}$ and $\beta_{5}$ subunits was slightly increased in $\mathrm{H} 460$ cells compared to SW1573 after $24 \mathrm{~h}$ exposure to bortezomib $(10,100 \mathrm{nM})$. Additionally, exposure to bortezomib induced expression of subunit $\beta_{1}$ in $\mathrm{H} 460$ cells as compared to untreated control. In agreement with our results, increased expression of proteasome subunits, as well increased (basal) proteasome activity, was recently related to resistance to proteasome inhibitor treatment [12].

To examine the possibility that apoptotic factors might explain the differential sensitivity for apoptosis induction once the proteasome has been effectively inhibited, we assessed the expression of heat shock proteins, such as Hsp27, Hsp70 and Hsp90 upon exposure of H460 and SW1573 cells to bortezomib. Notably the expression of Hsp27, but also Hsp90, was higher in SW1573 cells than in $\mathrm{H} 460$ cells, correlating with less pronounced apoptosis in SW1573 cells. The expression levels of Hsp70 was similar in both cell lines.

NSCLC cell lines display differential sensitivity towards the proteasome inhibitor bortezomib. For effective induction and execution of apoptosis at least two conditions must be met. First, the dose of bortezomib must be above the threshold necessary to inhibit the proteasome activity in individual NSCLC cells. We showed that this threshold concentration differs among non-small cell lung cancer cells. Typically in clinical studies, proteasome inhibition 
in peripheral blood mononuclear cells is taken as a surrogate pharmacodynamic marker. These results indicate however that this might not be a fair estimate of what is occurring in the actual tumour tissue, as the proteasomal phenotype of individual tumours is subject to significant variability $[23,24]$.

Secondly, upon inhibition of the proteasome, an intrinsic or acquired resistance to apoptosis must be overcome, the apoptotic phenotype being variable in different NSCLC cell lines. In this regard, apoptosis resistance does not directly correlate with resistance resulting from a differential proteasomal phenotype, as was shown in SW1573 cells, which were more sensitive to proteasome inhibition, but more resistant to apoptosis than H460 cells. Additionally, H460 cells overexpressing anti-apoptotic Bcl-2 showed a similar proteasomal phenotype as did wild type H460 cells. Increased apoptosis resistance of SW1573 cells compared to H460 cells might result from increased expression of Hsp27 in SW1573 cells, which has been postulated to be a resistance factor for bortezomibinduced cell death [14].

It was recently suggested in a mice model of colon carcinoma, that potentiation of the anticancer activity of bortezomib by combination with TNF- $\alpha$ resulted from reduced expression of proteasome subunits and inhibition of Hsp27 [25]. Breast carcinoma cells were shown to be more resistant to treatment with bortezomib than normal breast cells, despite a higher level of feedback proteasome upregulation in the normal cells. The authors suggested resistance of the cancer cells compared to the normal cells was primarily due to a defective pathway of bortezomib-induced apoptosis in the cancer cells [11]. Another report suggested resistance to bortezomib can occur in lymphoma cells through an altered proteasomal phenotype coinciding with increased expression and altered subunit composition of proteasome [12]. Our preliminary results indicate that also $\mathrm{H} 460$ cells can adapt to continuous incremental exposure of bortezomib (data not shown).

Additionally, we recommend an assay allowing cell fraction measurement, such as PI-staining based FACS analysis, over an anti-proliferative assay, such as MTT, to characterise the cytotoxic effects of proteasome inhibitors. Cell fraction measurement by PI-staining based FACS analysis is informative about the apoptosis inducing

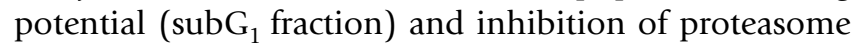
activity $\left(\mathrm{G}_{2} \mathrm{M}\right.$ arrest). In contrast, a low $\mathrm{IC}_{50}$ (e.g. SW1573 cells), as determined by MTT assay, does not necessarily correspond to enhanced apoptosis induction in a certain cell line, compared to a cell line with a higher $\mathrm{IC}_{50}$ (e.g., H460 cells).
Our preliminary results show that the proteasomal as well as apoptotic phenotype determines bortezomib sensitivity in NSCLC cells. There is a preclinical rationale to combine proteasome inhibition with pro-apoptotic agents as well as agents promoting a more favourable proteasomal phenotype to overcome this resistance $[20,26]$.

\section{Materials and methods Cell lines and drugs}

NSCLC cell lines H292, H460, H1299, H322, A549, H1703 and SW1573 were obtained from the American Type Culture Collection (Manassas, VA, USA) and cultured in RPMI1640 or, SW1573 only, DMEM (Cambrex Bioscience, Verviers, Belgium). H460 cells stably overexpressing Bcl-2 (H460-Bcl-2) were generated previously [27]. Culture mediums were supplemented with $10 \%$ FCS, $100-$ units $/ \mathrm{ml}$ penicillin, and $100-\mu \mathrm{g} / \mathrm{ml}$ streptomycin (Invitrogen, Breda, The Netherlands). Bortezomib $\left(\right.$ Velcade $^{\mathrm{TM}}$ ) (Millennium Pharmaceuticals Inc. Cambridge, MA, USA) was dissolved in DMSO.

\section{Growth inhibition assay}

Growth inhibition was determined $72 \mathrm{~h}$ after treatment with a concentration range of bortezomib, by MTT assay, as described previously [15]. Results are presented as percentage of survival taking the control (untreated cells) as $100 \%$ survival. The concentration resulting in $50 \%$ of cellgrowth inhibition $\left(\mathrm{IC}_{50}\right)$ was calculated using SigmaPlot version 8.0 software (SPSS Inc., Chicago, IL, USA).

\section{Flow cytometric analysis of PI-stained cells}

Propidium iodide (PI) staining and flow cytometry analysis were performed as described previously [15]. The fraction of cells with hypodiploid DNA content was considered as the apoptotic cell population. Cell cycle fractions were estimated using WinMDI Version 2.9 (The Scripps Research Institute, La Jolla, CA, USA) and Cylchred (Cardiff University, Cardiff, UK) version 1.0.2 software.

\section{Proteasome activity assay}

The chymotryptic activity of the proteasome was estimated as described previously [15], using succinyl-LeuLeu-Val-Tyr-AMC substrate (Bachem, King of Prussia, PA, USA). Fluorescence of the released 7-amido-4-methylcoumarin dye was measured on a SpectraFluor multiwell plate reader (Tecan, Salzburg, Austria), set at an excitation wavelength $380 \mathrm{~nm}$ and emission wavelength $460 \mathrm{~nm}$.

\section{Western blot analysis}

Western blot analysis was performed as described before [15]. Rabbit polyclonal antibodies used were: anti-Hsp70 (Affinity Bioreagents, Golden, CO, USA), anti-Hsp90 (Cell Signaling, Danvers, MA, USA), anti-20S proteasome core, anti-subunit $\beta_{1}, \beta_{2}, \beta_{5}$ (Biomol, Plymouth Meeting, 
PA, USA), anti-Mcl-1 (clone 22, BD PharMingen, San Diego, CA, USA), mouse monoclonal antibodies used were: anti-Hsp27 (Cell Signaling), anti- $\beta$-actin (SigmaAldrich, St Louis, MO, USA).

\section{Competing interests}

The author(s) declare that they have no competing interests.

\section{Authors' contributions}

JV conceived of the studies, carried out experimental assays, analyzed data and drafted the manuscript. AC carried out experimental assays and drafted the manuscript. GG initiated the studies and drafted the manuscript. All authors read and approved the final manuscript.

\section{Acknowledgements}

Supported in part by the Netherlands Organization of Scientific Research ZonMW/NWO-AGIKO grant 920-03-290 (JV).

\section{References}

I. Hershko A, Ciechanover A: The Ubiquitin System. Annual Review of Biochemistry 1998, 67:425-479.

2. King RW, Deshaies RJ, Peters JM, Kirschner MW: How proteolysis drives the cell cycle. Science 1996, 274:1652-1659.

3. Adams J: The proteasome: a suitable antineoplastic target. Nat Rev Cancer 2004, 4:349-360.

4. Schwartz AL, Ciechanover A: The ubiquitin-proteasome pathway and pathogenesis of human diseases. Annu Rev Med 1999, 50:57-74.

5. Jemal A, Siegel R, Ward E, Murray T, Xu J, Thun MJ: Cancer statistics, 2007. CA Cancer J Clin 2007, 57:43-66.

6. Fanucchi MP, Fossella FV, Belt R, Natale R, Fidias P, Carbone DP, Govindan R, Raez LE, Robert F, Ribeiro M, Akerley W, Kelly K, Limentani SA, Crawford J, Reimers HJ, Axelrod R, Kashala O, Sheng $\mathrm{S}$, Schiller $\mathrm{JH}$ : Randomized phase II study of bortezomib alone and bortezomib in combination with docetaxel in previously treated advanced non-small-cell lung cancer. J Clin Oncol 2006, 24:5025-5033.

7. Scagliotti G: Proteasome inhibitors in lung cancer. Crit Rev Oncol Hematol 2006, 58:177-189.

8. Politou M, Karadimitris A, Terpos E, Kotsianidis I, Apperley JF, Rahemtulla A: No evidence of mutations of the PSMB5 (beta5 subunit of proteasome) in a case of myeloma with clinical resistance to Bortezomib. Leuk Res 2006, 30:240-24I.

9. Hideshima T, Chauhan D, Ishitsuka K, Yasui H, Raje N, Kumar S, Podar K, Mitsiades C, Hideshima H, Bonham L, Munshi NC, Richardson PG, Singer JW, Anderson KC: Molecular characterization of PS-34I (bortezomib) resistance: implications for overcoming resistance using lysophosphatidic acid acyltransferase (LPAAT)-beta inhibitors. Oncogene 2005, 24:312I-3I29.

10. Chauhan D, Hideshima T, Anderson KC: A novel proteasome inhibitor NPI-0052 as an anticancer therapy. Br J Cancer 2006, 95:961-965.

II. $\mathrm{Xu} \mathrm{H}$, Ju D, Jarois $\mathrm{T}, \mathrm{Xie} \mathrm{Y}$ : Diminished feedback regulation of proteasome expression and resistance to proteasome inhibitors in breast cancer cells. Breast Cancer Res Treat 2007, doi: $|0.1007 / \mathrm{s}|$ 0549-007-9553-4.

12. Fuchs D, Berges C, Opelz G, Daniel V, Naujokat C: Increased expression and altered subunit composition of proteasomes induced by continuous proteasome inhibition establish apoptosis resistance and hyperproliferation of Burkitt lymphoma cells. J Cell Biochem 2007, I4:1605-1616

13. Kraus M, Ruckrich T, Reich M, Gogel J, Beck A, Kammer W, Berkers $C R$, Burg D, Overkleeft H, Ovaa H, Driessen C: Activity patterns of proteasome subunits reflect bortezomib sensitivity of hematologic malignancies and are variable in primary human leukemia cells. Leukemia 2007, 2 I:84-92.
14. Chauhan D, Li G, Shringarpure R, Podar K, Ohtake Y, Hideshima T, Anderson KC: Blockade of Hsp27 Overcomes Bortezomib/ Proteasome Inhibitor PS-34I Resistance in Lymphoma Cells. Cancer Res 2003, 63:6174-6I77.

I5. Voortman J, Checinska A, Giaccone G, Rodriguez JA, Kruyt FA: Bortezomib, but not cisplatin, induces mitochondria-dependent apoptosis accompanied by up-regulation of noxa in the nonsmall cell lung cancer cell line NCl-H460. Mol Cancer Ther 2007, 6:1046-1053.

16. Mimnaugh EG, Xu W, Vos M, Yuan X, Isaacs JS, Bisht KS, Gius D, Neckers L: Simultaneous inhibition of hsp 90 and the proteasome promotes protein ubiquitination, causes endoplasmic reticulum-derived cytosolic vacuolization, and enhances antitumor activity. Mol Cancer Ther 2004, 3:55I-566.

17. Shringarpure R, Catley L, Bhole D, Burger R, Podar K, Tai YT, Kessler B, Galardy P, Ploegh H, Tassone P, Hideshima T, Mitsiades C, Munshi NC, Chauhan D, Anderson KC: Gene expression analysis of Blymphoma cells resistant and sensitive to bortezomib. $\mathrm{Br}$ Haematol 2006, I 34: I45-156.

18. Ling YH, Liebes L, Jiang JD, Holland JF, Elliott PJ, Adams J, Muggia FM, Perez-Soler R: Mechanisms of proteasome inhibitor PS-34Iinduced $\mathbf{G ( 2 ) - M - p h a s e ~ a r r e s t ~ a n d ~ a p o p t o s i s ~ i n ~ h u m a n ~ n o n - ~}$ small cell lung cancer cell lines. Clin Cancer Res 2003, 9:1145-II54.

19. Voortman J, Resende TP, Abou El Hassan MA, Giaccone G, Kruyt FA: TRAIL therapy in non-small cell lung cancer cells: sensitization to death receptor-mediated apoptosis by proteasome inhibitor bortezomib. Mol Cancer Ther 2007, 6:2 103-2II 2.

20. Wolter KG, Verhaegen M, Fernandez Y, Nikolovska-Coleska Z, Riblett M, Martin de la Vega C, Wang S, Soengas MS: Therapeutic window for melanoma treatment provided by selective effects of the proteasome on Bcl-2 proteins. Cell Death Differ 2007, I4:1605-1616.

21. Berkers CR, Verdoes M, Lichtman E, Fiebiger E, Kessler BM, Anderson KC, Ploegh HL, Ovaa H, Galardy PJ: Activity probe for in vivo profiling of the specificity of proteasome inhibitor bortezomib. Nat Methods 2005, 2:357-362.

22. Crawford LJ, Walker B, Ovaa H, Chauhan D, Anderson KC, Morris TC, Irvine AE: Comparative selectivity and specificity of the proteasome inhibitors BzLLLCOCHO, PS-34I, and MG-I 32. Cancer Res 2006, 66:6379-6386.

23. Altun M, Galardy PJ, Shringarpure R, Hideshima T, LeBlanc R, Anderson KC, Ploegh HL, Kessler BM: Effects of PS-34I on the activity and composition of proteasomes in multiple myeloma cells. Cancer Res 2005, 65:7896-7901.

24. Bandoh N, Ogino T, Cho HS, Hur SY, Shen J, Wang X, Kato S, Miyokawa N, Harabuchi Y, Ferrone S: Development and characterization of human constitutive proteasome and immunoproteasome subunit-specific monoclonal antibodies. Tissue Antigens 2005, 66:185-194.

25. Nowis D, McConnell EJ, Dierlam L, Palamarchuk A, Lass A, Wojcik C: TNF potentiates anticancer activity of bortezomib (Velcade(R)) through reduced expression of proteasome subunits and dysregulation of unfolded protein response. Int $\mathrm{J}$ Cancer 2007, I $21: 43$ I-44I.

26. Sydor JR, Normant E, Pien CS, Porter JR, Ge J, Grenier L, Pak RH, Ali JA, Dembski MS, Hudak J, Patterson J, Penders C, Pink M, Read MA, Sang J, Woodward C, Zhang Y, Grayzel DS, Wright J, Barrett JA, Palombella VJ, Adams J, Tong JK: Development of I 7-allylamino-I 7 demethoxygeldanamycin hydroquinone hydrochloride (IPI504), an anti-cancer agent directed against Hsp90. PNAS 2006, 103:17408-174I3.

27. Ferreira CG, Span SW, Peters GJ, Kruyt FAE, Giaccone G: Chemotherapy Triggers Apoptosis in a Caspase-8-dependent and Mitochondria-controlled Manner in the Non-Small Cell Lung Cancer Cell Line NCI-H460. Cancer Res 2000, 60:7133-7I4I. 